\title{
Flexible Pavement Design Simulation Using Mechanistic-Empirical Pavement Design Guide
}

\author{
Daba S. Gedafa ${ }^{1}$, Mustaque Hossain ${ }^{2}$, Stefan Romanoschi ${ }^{3}$ and Andrew J. Gisi ${ }^{4}$ \\ 1. Department of Civil Engineering, University of North Dakota, Grand Forks ND 58202-8115, USA \\ 2. Department of Civil Engineering, Kansas State University, Manhattan KS 66506, USA \\ 3. Department of Civil Engineering, University of Texas-Arlington, Arlington TX 76019-0308, USA \\ 4. Kansas Department of Transportation, Materials and Research Center, Topeka KS 66611, USA
}

\begin{abstract}
The KDOT (Kansas Department of Transportation) is currently adopting MEPDG (mechanistic-empirical pavement design guide) to replace the 1993 AASHTO (American Association of State Highway and Transportation Officials) design method. The main objective of this study was to compare flexible pavement design using 1993 AASHTO design guide and MEPDG. Five newly built Superior PERforming Asphalt PAVEments (Superpave), designed using the 1993 AASHTO Design Guide, were selected as test sections for the design simulation study. Deflection data were collected approximately 8 to 10 weeks after construction using FWD (falling weight deflectometer). The FWD deflection data were used to back-calculate the pavement layer moduli using three different back-calculation programs. The existing pavement structures were analyzed for a 10-year analysis period. The maximum numbers of years the existing pavement structures will be in a serviceable condition as well as the minimum thicknesses of different layers to serve for 10-years were also determined. Effects of changing subgrade modulus, target distress, and reliability were also investigated. The MEPDG design analysis shows that the 1993 AASHTO Guide-designed flexible pavements do not show the distresses currently observed in Kansas for the 10-year design period. The MEPDG design simulation shows that the thinner the pavement sections, the higher the permanent deformation. The existing pavement structures can serve for more than 20 years as per the MEPDG design analysis if the default failure criteria and nationally-calibrated models are used.
\end{abstract}

Key words: Pavement design, MEPDG, 1993 AASHTO design guide, FWD deflection, back-calculated modulus.

\section{Introduction}

The most widely used procedure for the design of flexible pavements is specified in the Guide for Design of Pavement Structures, published in 1986 and 1993, by the AASHTO (American Association of State Highway and Transportation Officials) [1, 2]. A few states use the 1972 AASHTO Interim Guide procedure, their own empirical or mechanistic-empirical procedures, or a design catalog [3]. The design methodologies in all those versions of the AASHTO Guide are based on the empirical performance equations developed using the AASHO

Corresponding author: Daba S. Gedafa, Ph.D., P.E., assistant professor, research fields: mechanistic-empirical design, pavement management system, non-destructive testing, materials engineering and traffic engineering. E-mail: daba.gedafa@engr.und.edu.
Road Test data from the late 1950s.

Due to the limitations of earlier guides, a design guide, based as fully as possible on mechanistic principles, was developed under the NCHRP (National Cooperative Highway Research Program) [4]. The procedure is capable of developing mechanistic-empirical design while accounting for local environmental conditions, local materials, and actual highway traffic distribution by means of axle load spectra. Since the resulting procedure is very sound and flexible and it considerably surpasses the capabilities of any currently available pavement design and analysis tools, it has been adopted by AASHTO as the new AASHTO design method for pavement structures.

The design method adopted in the Guide for 
Mechanistic-Empirical Design of New and Rehabilitated Pavement Structures is known as MEPDG (Mechanistic-Empirical Pavement Design Guide). In MEPDG, prediction of pavement response and performance must take into account fundamental properties of layer materials. Among fundamental layer properties, the most important property of HMA (hot-mix asphalt) is the dynamic modulus of asphalt concrete. This property represents the temperatureand time-dependent stiffness characteristics of the HMA material. Significant amount of effort has been devoted to develop a test protocol to determine the dynamic modulus of HMA [5]. This effort has resulted in a standard test protocol that can be used for the Simple Performance Test for Superpave ${ }^{\circledR}$ Mix Design [6]. This test protocol calls for the use of axial compression testing for measuring the dynamic modulus. One of the issues related to the dynamic modulus is its use in forensic studies and pavement rehabilitation design.

In the hierarchical design approach proposed in MEPDG for new HMA pavements, dynamic moduli measured in laboratory are required for the highest design reliability (Level 1), which is intended for pavements with very high traffic volumes. However, dynamic modulus is used as the primary stiffness property for HMA at all three levels of hierarchical inputs in MEPDG. The dynamic modulus test is relatively difficult and expensive to perform. Therefore, numerous attempts have been made to develop regression equations to estimate the dynamic modulus from mixture volumetric properties. The predictive equation developed by Witczak et al. [5] is one of the most comprehensive mixture dynamic modulus models available today that can predict the dynamic modulus of dense-graded HMA mixtures over a range of temperatures, rates of loading and aging conditions. These inputs are available from conventional binder tests and the volumetric properties of the HMA mixture. A revised version of this model has been recommended in the design of intermediate- and low-volume roadways (design Levels 2 and 3) in MEPDG [7].

The KDOT (Kansas Department of Transportation) is currently considering adopting MEPDG to replace the 1993 AASHTO design method that is in use now. However, work is needed to determine whether MEPDG gives results similar to that of the AASHTO design method and/or predict the distresses that match the measured/observed distresses.

\section{Objectives}

The main objectives of this study are to investigate:

(1) The AASHTO flexible pavement design method in Kansas using MEPDG;

(2) The effect of subgrade modulus on the predicted distresses using MEPDG;

(3) The effect of failure criteria and reliability while using MEPDG.

\section{Test Sections}

Five newly built superpave pavements, designed using the 1993 AASHTO Design Guide were selected in this study. Each test section was $305 \mathrm{~m}$ long. Table 1

Table 1 Layer type and thickness.

\begin{tabular}{|c|c|c|c|c|c|c|c|}
\hline \multirow[b]{2}{*}{ Layer No. } & \multirow[b]{2}{*}{ Layer type } & \multirow[b]{2}{*}{ Material type } & \multicolumn{5}{|c|}{ Thickness $(\mathrm{cm})$} \\
\hline & & & $\begin{array}{l}\text { US-54 } \\
\text { Butler }\end{array}$ & $\begin{array}{l}\text { US-77 } \\
\text { Butler }\end{array}$ & $\begin{array}{l}\text { US-283 } \\
\text { Grah. }\end{array}$ & $\begin{array}{l}\text { K-7 } \\
\text { Don. }\end{array}$ & $\begin{array}{l}\text { K-99 } \\
\text { Elk }\end{array}$ \\
\hline 1 & Surface & SM-9.5A (PG 64-28) & $3.8^{\mathrm{a}}$ & 3.8 & 3.8 & 3.8 & 3.8 \\
\hline 2 & Binder & SM-19A (PG 64-28) & 6.3 & 6.3 & 6.3 & 6.3 & 6.3 \\
\hline 3 & Base & SM-19A (PG 64-22) & 21.3 & 20.0 & 17.5 & 12.5 & 17.5 \\
\hline 4 & Aggregate base & $\mathrm{AB}-3$ & $\mathrm{~N} / \mathrm{A}$ & $\mathrm{N} / \mathrm{A}$ & $\mathrm{N} / \mathrm{A}$ & 27.5 & $\mathrm{~N} / \mathrm{A}$ \\
\hline 5 & Subgrade & Modified subgrade & $15.0^{\mathrm{b}}$ & $15.0^{\mathrm{b}}$ & $15.0^{\mathrm{b}}$ & $15.0^{\mathrm{c}}$ & $15.0^{\mathrm{b}}$ \\
\hline
\end{tabular}

${ }^{\mathrm{a}} \mathrm{SM}-9.5 \mathrm{~T}$ PG $64-28 ;{ }^{\mathrm{b}}$ Lime Treated Subgrade (LTSG); ${ }^{\mathrm{c}}$ fly ash modified subgrade (FASG). 
shows the layer type and thicknesses of these sections.

All pavement sections have Superpave $9.5 \mathrm{~mm}$ nominal maximum aggregate size mixture (known as SM-9.5A and SM-9.5T in Kansas) with PG 64-28 binder in the surface course of $3.8 \mathrm{~cm}$ thickness. Layers 2 and 3 consist of fine graded Superpave 19 $\mathrm{mm}$ nominal maximum aggregate size mixture, SM-19A with PG 64-28 and PG 64-22 binders, respectively. The base layer thickness varies from $12.5 \mathrm{~cm}$ to $21.3 \mathrm{~cm}$. The K-7 project in Doniphan County has the thinnest asphalt base $(12.5 \mathrm{~cm})$ since it also has $27.5 \mathrm{~cm}$ crushed stone base, designated as AB-3 in Kansas. All projects have lime-treated subgrade except K-7 in Doniphan County where subgrade was modified with a Class $\mathrm{C}$ fly ash.

\section{Data Collection}

\subsection{Deflection Data}

Deflection data were collected approximately 8 to 10 weeks after construction. Multiple target loads were used on most test sections. The target loads used in the FWD (falling weight deflectometer) testing were 40, 53 and/or $67 \mathrm{kN}$ for all sections. Deflection measurements were made in the outside wheel path of the travel lane at 11 stations at $30.5 \mathrm{~m}$ intervals. The geophone spacing was $0,20,30,45,60,90$ and 120 $\mathrm{cm}$ for US-54, US-77 and US-283. The last sensor was located at $150 \mathrm{~cm}$ for the K-7 and K-99 projects.

\subsection{Volumetric Properties}

Most of the mixture data required have been obtained from the mix design database of KDOT. Information includes gradation of aggregates (cumulative percent retained on $19 \mathrm{~mm}, 9.5 \mathrm{~mm}$ and $4.75 \mathrm{~mm}$ sieves and percent passing $0.075 \mathrm{~mm}$ sieve), physical properties of the aggregates (bulk and effective specific gravities), asphalt content and asphalt specific gravity and theoretical maximum specific gravity of the mixture.

Bulk specific gravities of the compacted samples and the cores were determined in the laboratory following the Kansas Standard Test Method KT-15, Procedure III. KT-15 closely follows AASHTO T 166. From these pieces of information, the air void (\%), effective binder content ( $\%$ by volume), voids in the mineral aggregates (VMA, \%), and percent of VMA filled with binder (\%) were calculated. The original, mix/lay-down, surface aging and aging at different viscosities have been determined at different temperature and frequency. Temperature data for different locations have been obtained from KSU (Kansas State University) weather data library.

\section{Analysis Methodology}

\subsection{Back-Calculation of Modulus}

FWD deflection data have been normalized to 40 $\mathrm{kN}$ load. These normalized deflection data were used to back-calculate the pavement layer moduli based on the multilayered elastic theory. The moduli of thin surface layers or sandwiched layers are usually difficult to obtain, because surface deflections are often insensitive to changes in the moduli of these layers. Changes in the moduli of subgrade or other thick layers may mask changes in thin layers [8]. Flexible pavements are usually analyzed as three-layered systems having an asphalt concrete surface layer, a mechanically or chemically stabilized base layer and a subgrade [9]. In this study, all pavement sections were modeled as three layer systems by combining all asphalt concrete layers into one layer. Comparison of solutions from different programs gives an idea of the range of solutions that can be expected [8]. Thus, three back-calculation computer programs, EVERCALC, MODCOMP 5, and MODULUS, were used in this study. It is to be noted that only back-calculated subgrade moduli have been used in this study.

In the back-calculation of pavement layer moduli, the objective is to identify a set of pavement layer moduli that would produce a deflection basin matching the measured deflection basin. Since only a finite number of sensor data points are available from 
the deflection measurements, the objective function in the back-calculation analysis typically involves the minimization of the root-mean-square difference $\left(D_{r m s}\right)$ of the measured and computed deflections. A solution that has a smaller $D_{r m s}$ value is considered to be a better fit, and thus a better solution [10].

$$
\text { Minimize } \quad D_{r m s}=\sqrt{\frac{1}{m} \sum_{i=1}^{m}\left(\frac{d_{i}-D_{i}}{D_{i}}\right)}
$$

where, $m=$ number of deflection-measurement points, $d_{i}=$ back-calculated deflection at point $\mathrm{i}$, and $D_{i}=$ measured deflection at point $\mathrm{i}$.

\subsection{Analysis Using MEPDG}

MEPDG software was used to do the design analysis. Four cases have been considered at level 3 using default distress targets. The existing pavement structure was analyzed for a 10 -year analysis period as Case 1. Case 2 considered the maximum number of years the existing pavement structure will be in a serviceable condition. Minimum thickness of different layers to serve for 10-years has been found by ignoring and considering longitudinal cracking as Cases 3 and 4, respectively.

Input data used for the MEPDG analysis of flexible pavements are categorized as: general information, site/projection identification, analysis parameters, traffic, climate, pavement structures and miscellaneous. The main ones are discussed below:

Analysis parameters: Flexible pavement design is based on the surface-down and bottom-up fatigue cracking of the asphalt surface, HMA thermal cracking, fatigue cracking in chemically stabilized layers, permanent deformation for both asphalt layers and the whole pavement and roughness. Since there are no stabilized layers in this study, fatigue cracking in chemically stabilized layers is not applicable. Default and modified criteria have been used in this study. Distress targets for 10-year design life have been changed for some of the distresses as shown in Table 2. Reliability was also changed to $50 \%$ keeping the default distress targets (not included in the table).

Traffic data: are one of the key elements required for the design and analysis of pavement structures. The basic required information are AADTT (annual average daily truck traffic) for the base year, percent trucks in the design direction, percent trucks in the design lane, and operational speed of the vehicles. Three functions are available to estimate future truck traffic volumes: no growth, linear growth and compound growth. Linear growth rate was used in this study.

Project-specific linear traffic growth rates varied from $0.9 \%$ to $1.7 \%$. Directional and lane distribution factor for trucks was taken as $60 \%$ and $100 \%$, respectively. Percent of trucks varies from $13 \%$ to $26 \%$ as indicated in Table 3. For this study, some other required traffic inputs (hourly distribution factor, monthly adjustment factor, axle load distribution factor, number of axles per truck, axle spacing, etc.) were derived from the MEPDG level 3 or default values.

Climate: Environmental conditions have significant effects on the performance of flexible pavements. The seasonal damage and distress accumulation algorithms

Table 2 Performance criteria for the study.

\begin{tabular}{llllll}
\hline \multirow{2}{*}{ Distress type } & \multicolumn{2}{c}{ Criteria $1 /$ default } & & \multicolumn{2}{c}{ Criteria 2 } \\
\cline { 2 - 3 } \cline { 5 - 6 } & Distress target & Reliability level (\%) & & Distress target & Reliability level (\%) \\
\hline Terminal IRI (m/km) & 2.6 & 90.0 & 2.6 & 90.0 \\
Long. cracking (m/km) & 189.4 & 90.0 & 90.0 & 94.7 & 90.0 \\
Alligator (fatigue) cracking (\%) & 25.0 & 90.0 & 10.0 & 90.0 \\
Transverse cracking (m/km) & 189.4 & 90.0 & 94.7 & 90.0 \\
AC permanent deformation $(\mathrm{cm})$ & 0.64 & 90.0 & 0.64 & 90.0 \\
Total permanent deformation $(\mathrm{cm})$ & 1.91 & & 1.91 & 90.0 \\
\hline
\end{tabular}


Table 3 Summary of traffic data.

\begin{tabular}{llllll}
\hline Routes & US-54 & US-77 & US-283 & K-7 & K-99 \\
\hline Initial two-way AADT & 3,959 & 1,217 & 1,046 & 1,251 & 1,862 \\
Percent of trucks & 13 & 26 & 20 & 14 & 16 \\
Linear growth rate (\%) & 1.5 & 1.4 & 0.9 & 1.4 & 1.7 \\
Operational speed (km/hr) & 110 & 95 & 105 & 90 & 90 \\
No. of lanes in each direction & 1 & 1 & 1 & 1 & 1 \\
Directional distribution (\%) & 60 & 60 & 60 & 60 & 60 \\
Lane distribution (\%) & 100 & 100 & 100 & 100 & 100 \\
\hline
\end{tabular}

in the MEPDG design methodology require hourly data for six weather parameters such as air temperature, precipitation, wind speed, percentage sunshine, relative humidity and seasonal or constant water table depth at the project site [4]. The design guide recommends that the weather inputs be obtained from weather stations located near the project site. At least 24 months of actual weather station data are required for the computations. In this study, project specific virtual weather stations were created by interpolation of climatic data from the selected physical weather stations.

Miscellaneous: The thermo-hydraulic properties required as inputs into MEPDG software are groundwater depth, infiltration and drainage properties, physical/index properties, hydraulic conductivity, thermal conductivity, heat capacity, etc.. The recommended calibrated values of $2.72 \mathrm{~W} /(\mathrm{m} . \mathrm{K})$ and $1.17 \mathrm{~kJ} /(\mathrm{kg} . \mathrm{K})$ were used for thermal conductivity and heat capacity, respectively. Physical and index properties were derived based on the gradation of the unbound materials. Surface shortwave absorptivity and drainage path length were chosen based on the default inputs, and was $0.85 \mathrm{~m}$ and $3.7 \mathrm{~m}$, respectively. All performance models used in this study are the nationally calibrated default ones. Only the inputs represent local conditions or projects in Kansas.

\section{Results and Discussion}

The existing pavement structures were analyzed for a 10 -year analysis period as Case 1 . Case 2 considered the maximum number of years the existing pavement structure will be in a serviceable condition. Minimum thickness of different layers to serve for 10-year has been found by ignoring and considering longitudinal cracking as Case 3 and 4, respectively. Default criteria have been used for these cases. Effects of changing subgrade modulus, target distress, and reliability have also been presented

\subsection{Case 1: 10-Year Analysis Period}

The predicted distresses for the existing pavement structures are shown in Table 4(a). These predicted distresses are far less than the target distress limits. The lowest and highest IRI (International Roughness Index) is $1.36 \mathrm{~m} / \mathrm{km}$ and $1.41 \mathrm{~m} / \mathrm{km}$, respectively. Longitudinal and transverse crack is zero and 0.19 $\mathrm{m} / \mathrm{km}$, respectively, for all projects. The thinner the pavement sections, the higher the $\mathrm{AC}$ and total permanent deformation.

\subsection{Maximum Design Life}

Table 4(b) shows the maximum number of years the existing pavement structure will be in a serviceable condition. $\mathrm{K}-7$ has the thinnest total $\mathrm{AC}$ thickness and as a result, it has the least service period. US-77 has the highest service period. The lowest and highest IRI is observed on US-283 and US-77, respectively. Insignificant amount of longitudinal cracking is observed on only K-99. The smallest and largest $\mathrm{AC}$ and total permanent deformation is observed on US-77 and K-99, respectively.

\subsection{Case 3: Minimum Thickness Ignoring Longitudinal Cracking}

The causes and effects of AC surface down cracking 
Table 4 Distress predicted for 10-year and maximum design life.

\begin{tabular}{|c|c|c|c|c|c|c|}
\hline & \multicolumn{5}{|c|}{ Predicted distress } & \multirow{2}{*}{-Distress target } \\
\hline & US-54 & US-77 & US-283 & $\mathrm{K}-7$ & K-99 & \\
\hline \multicolumn{7}{|c|}{ (a) 10-year design life } \\
\hline IRI $(\mathrm{m} / \mathrm{km})$ & 1.37 & 1.36 & 1.38 & 1.41 & 1.40 & 2.59 \\
\hline Long. cracking (m/km) & 0.00 & 0.00 & 0.00 & 0.00 & 0.00 & 189.39 \\
\hline Alligator (fatigue) cracking (\%) & 0.00 & 0.00 & 0.00 & 0.10 & 0.10 & 25.00 \\
\hline Transverse cracking $(\mathrm{m} / \mathrm{km})$ & 0.19 & 0.19 & 0.19 & 0.19 & 0.19 & 189.39 \\
\hline AC permanent deformation $(\mathrm{cm})$ & 0.20 & 0.13 & 0.18 & 0.23 & 0.23 & 0.64 \\
\hline Total permanent deformation $(\mathrm{cm})$ & 0.73 & 0.70 & 0.78 & 0.83 & 0.85 & 1.91 \\
\hline \multicolumn{7}{|c|}{ (b) Maximum design life } \\
\hline Maximum design life (year) & 24 & 25 & 23 & 22 & 23 & \\
\hline IRI $(\mathrm{m} / \mathrm{km})$ & 1.90 & 1.92 & 1.87 & 1.89 & 1.90 & 2.60 \\
\hline Long. cracking $(\mathrm{m} / \mathrm{km})$ & 0.00 & 0.00 & 0.00 & 0.00 & 0.02 & 189.40 \\
\hline Alligator (fatigue) cracking (\%) & 0.10 & 0.00 & 0.10 & 0.10 & 0.40 & 25.00 \\
\hline Transverse cracking $(\mathrm{m} / \mathrm{km})$ & 0.19 & 0.19 & 0.19 & 0.00 & 0.19 & 189.40 \\
\hline AC permanent deformation $(\mathrm{cm})$ & 0.30 & 0.20 & 0.25 & 0.33 & 0.35 & 0.64 \\
\hline Total permanent deformation $(\mathrm{cm})$ & 0.93 & 0.88 & 0.95 & 1.03 & 1.10 & 1.91 \\
\hline
\end{tabular}

Table 5 Minimum layer thicknesses ignoring and considering longitudinal cracking.

\begin{tabular}{|c|c|c|c|c|c|c|}
\hline & & \multicolumn{5}{|c|}{ Predicted distress } \\
\hline & & US-54 & US-77 & US-283 & $\mathrm{K}-7$ & K-99 \\
\hline \multicolumn{7}{|c|}{ (a) Ignoring longitudinal cracking } \\
\hline \multirow{4}{*}{ Layer thickness } & Surface $(\mathrm{cm})$ & 3.75 & 3.75 & 3.75 & 2.50 & 3.75 \\
\hline & Binder $(\mathrm{cm})$ & 5.00 & 5.00 & 5.00 & 2.50 & 6.25 \\
\hline & Base $(\mathrm{cm})$ & 5.00 & 2.50 & 2.50 & 2.50 & 5.00 \\
\hline & $\mathrm{AB} 3(\mathrm{~cm})$ & - & - & - & 27.50 & - \\
\hline \multirow{6}{*}{ Distresses } & IRI $(\mathrm{m} / \mathrm{km})$ & 1.58 & 1.61 & 1.59 & 1.61 & 1.56 \\
\hline & Long. cracking (m/km) & 158.90 & 191.29 & 181.63 & 11.95 & 806.80 \\
\hline & Alligator (fatigue) cracking (\%) & 6.10 & 4.70 & 3.80 & 1.40 & 5.70 \\
\hline & Transverse cracking (m/km) & 0.19 & 0.19 & 0.19 & 0.19 & 0.19 \\
\hline & AC permanent deformation $(\mathrm{cm})$ & 0.38 & 0.35 & 0.28 & 0.33 & 0.33 \\
\hline & Total permanent deformation $(\mathrm{cm})$ & 1.35 & 1.50 & 1.45 & 1.48 & 1.30 \\
\hline \multicolumn{7}{|c|}{ (b) Considering longitudinal cracking } \\
\hline \multirow{5}{*}{ Layer thickness } & Surface $(\mathrm{cm})$ & 3.75 & 3.75 & 3.75 & 3.75 & 3.75 \\
\hline & Binder $(\mathrm{cm})$ & 5.00 & 5.00 & 6.25 & 6.25 & 6.25 \\
\hline & Base $(\mathrm{cm})$ & 10.00 & 7.50 & 8.75 & 5.00 & 12.50 \\
\hline & Total AC thickness $(\mathrm{cm})$ & 18.75 & 16.25 & 18.75 & 15.00 & 22.50 \\
\hline & $\mathrm{AB} 3(\mathrm{~cm})$ & - & - & - & 27.50 & - \\
\hline \multirow{6}{*}{ Distresses } & IRI (m/km) & 1.46 & 1.45 & 1.44 & 1.47 & 1.44 \\
\hline & Long. cracking (m/km) & 0.55 & 1.67 & 0.49 & 0.78 & 1.67 \\
\hline & Alligator (fatigue) cracking (\%) & 0.70 & 0.40 & 0.20 & 0.40 & 0.50 \\
\hline & Transverse cracking $(\mathrm{m} / \mathrm{km})$ & 0.19 & 0.19 & 0.19 & 0.19 & 0.19 \\
\hline & AC permanent deformation $(\mathrm{cm})$ & 0.30 & 0.20 & 0.20 & 0.25 & 0.28 \\
\hline & Total permanent deformation $(\mathrm{cm})$ & 1.05 & 1.05 & 1.00 & 1.05 & 1.00 \\
\hline
\end{tabular}

(longitudinal cracking) are not well understood yet and it was ignored (there has been failure in longitudinal cracking) in this case to determine the minimum thicknesses of different layers to serve for 10-year as shown in Table 5(a). The lowest to highest total AC thickness to serve for 10-year is $7.5,11.25$, 
$11.25,13.75$ and $15 \mathrm{~cm}$ for K-7, US-283, US-77, US-54 and K-99, respectively. K-7 has the lowest total AC thickness since it has $27.5 \mathrm{~cm}$ of AB-3. K-7 and US-54 has the lowest and highest alligator cracking, respectively. US-283 and US-54 has the lowest and highest AC permanent deformation whereas K-99 and US-54 has the lowest and the highest total permanent deformation, respectively.

\subsection{Case 4: Minimum Thickness Considering Longitudinal Cracking}

Minimum layer thicknesses of different layers to serve for a 10 -year period considering the longitudinal cracking are shown in Table 5(b). The lowest to highest total AC thickness is $15,16.25,18.75,18.75$ and $22.5 \mathrm{~cm}$ for K-7, US-77, US-54, US-283 and $\mathrm{K}-99$, respectively. The lowest total AC thickness is observed for K-7, which has $27.5 \mathrm{~cm}$ of AB-3. The lowest IRI is observed on a pavement which has the highest total AC thickness (K-99) and vice versa (K-7) even though the difference is not significant from a practical point of view. This shows that longitudinal cracking does not depend on the thickness of AC layers. Transverse cracking is constant for all projects. US-283 has the lowest $\mathrm{AC}$ and total permanent deformation.

\subsection{Effect of Subgrade Modulus on Predicted Distress}

Back-calculation programs, EVERCALC, MODCOMP 5, and MODULUS, have been used to back-calculate the subgrade modulus. One-third of the back-calculated subgrade modulus was used as the subgrade design modulus to run the MEPDG software for a 10-year design analysis period. Default failure criteria have been used for this analysis. The results for different projects have been presented and discussed below:

US-54: The design subgrade modulus varies from 14.63 MPa to 188.68 MPa for US-54 as indicated in Table 6(a). Transverse and longitudinal cracking remain the same at all subgrade moduli. IRI, alligator cracking, and total permanent deformation decrease with an increase in subgrade modulus whereas the AC permanent deformation increases/remains constant with an increase in subgrade modulus. No failure has been observed at any subgrade modulus level;

US-77: Table 6(b) shows that the design subgrade modulus for US-77 varies from 7.90 $\mathrm{MPa}$ to 66.89 $\mathrm{MPa}$. Transverse and longitudinal cracking remain the same at all subgrade moduli. IRI, alligator cracking and total permanent deformation decrease with an increase in subgrade modulus whereas AC permanent deformation increases/remains constant with an increase in subgrade modulus. There is a failure in total pavement deformation when subgrade modulus is $7.90 \mathrm{MPa}$. The result shows that the stronger the subgrade, the higher the AC permanent deformation;

US-283: The design subgrade modulus varies from 7.76 MPa to $59.80 \mathrm{MPa}$ for US-283 as indicated in Table 6(c). Transverse and longitudinal cracking remain the same at all subgrade modulus levels. IRI, alligator cracking and total permanent deformation decrease with an increase in subgrade modulus whereas the AC permanent deformation increases/remains constant with an increase in subgrade modulus. There is failure due to total pavement deformation when the subgrade modulus is $7.76 \mathrm{MPa}$;

K-7: The design subgrade modulus varies from 43.75 MPa to 69.37 MPa for K-7 as indicated in Table 6(d). Transverse cracking, longitudinal cracking and AC permanent deformation remain the same at all subgrade modulus. IRI, alligator cracking and total permanent deformation decrease with an increase in subgrade modulus. There is no failure at any subgrade modulus level;

K-99: For K-99, the design subgrade modulus varies from 45.29 $\mathrm{MPa}$ to $69.92 \mathrm{MPa}$ as indicated in Table 6(e). Transverse cracking remains constant at all subgrade modulus. IRI, alligator cracking and AC permanent deformation decrease with an increase in subgrade modulus whereas longitudinal cracking and 
Table 6 Effect of subgrade modulus on predicted distresses.

\begin{tabular}{|c|c|c|c|c|c|}
\hline & \multicolumn{5}{|c|}{ Predicted distress } \\
\hline \multicolumn{6}{|c|}{ (a) US-54 } \\
\hline Design subgrade modulus (MPa) & 14.63 & 25.56 & 28.34 & 35.59 & 188.68 \\
\hline IRI (m/km) & 1.56 & 1.46 & 1.44 & 1.41 & 1.30 \\
\hline Long. cracking (m/km) & 0.00 & 0.00 & 0.00 & 0.00 & 0.00 \\
\hline Alligator cracking (\%) & 0.20 & 0.10 & 0.10 & 0.10 & 0.00 \\
\hline Transverse cracking (m/km) & 0.19 & 0.19 & 0.19 & 0.19 & 0.19 \\
\hline AC permanent deformation $(\mathrm{cm})$ & 0.18 & 0.20 & 0.20 & 0.20 & 0.20 \\
\hline Total permanent deformation $(\mathrm{cm})$ & 1.48 & 1.08 & 1.03 & 0.90 & 0.45 \\
\hline \multicolumn{6}{|c|}{ (b) US-77 } \\
\hline Design subgrade modulus (MPa) & 7.90 & 14.19 & 21.18 & 66.89 & \\
\hline IRI (m/km) & 1.72 & 1.56 & 1.48 & 1.33 & \\
\hline Long. cracking (m/km) & 0.00 & 0.00 & 0.00 & 0.00 & \\
\hline Alligator Cracking (\%) & 0.10 & 0.10 & 0.00 & 0.00 & \\
\hline Transverse Cracking (m/km) & 0.19 & 0.19 & 0.19 & 0.19 & \\
\hline AC permanent deformation $(\mathrm{cm})$ & 0.10 & 0.13 & 0.13 & 0.13 & \\
\hline Total permanent deformation $(\mathrm{cm})$ & $2.10^{*}$ & 1.48 & 1.15 & 0.60 & \\
\hline \multicolumn{6}{|c|}{ (c) US-283 } \\
\hline Design subgrade modulus (MPa) & 7.76 & 18.73 & 45.35 & 53.74 & 59.80 \\
\hline IRI (m/km) & 1.79 & 1.54 & 1.39 & 1.38 & 1.40 \\
\hline Long. cracking (m/km) & 0.00 & 0.00 & 0.00 & 0.00 & 0.00 \\
\hline Alligator cracking (\%) & 0.10 & 0.10 & 0.00 & 0.00 & 0.00 \\
\hline Transverse cracking (m/km) & 0.19 & 0.19 & 0.19 & 0.19 & 0.19 \\
\hline AC permanent deformation $(\mathrm{cm})$ & 0.15 & 0.15 & 0.18 & 0.18 & 0.23 \\
\hline Total permanent deformation $(\mathrm{cm})$ & $2.38^{*}$ & 1.38 & 0.83 & 0.75 & 0.80 \\
\hline \multicolumn{6}{|c|}{ (d) $\mathrm{K}-7$} \\
\hline Design subgrade modulus (MPa) & 43.75 & 52.32 & 64.50 & 69.37 & \\
\hline IRI (m/km) & 1.43 & 1.42 & 1.40 & 1.39 & \\
\hline Long. cracking (m/km) & 0.00 & 0.00 & 0.00 & 0.00 & \\
\hline Alligator cracking (\%) & 0.10 & 0.10 & 0.00 & 0.00 & \\
\hline Transverse cracking (m/km) & 0.19 & 0.19 & 0.19 & 0.19 & \\
\hline AC permanent deformation $(\mathrm{cm})$ & 0.23 & 0.23 & 0.23 & 0.23 & \\
\hline Total permanent deformation $(\mathrm{cm})$ & 0.93 & 0.85 & 0.78 & 0.75 & \\
\hline \multicolumn{6}{|c|}{ (e) K-99 } \\
\hline Design subgrade modulus (MPa) & 45.29 & 46.29 & 69.92 & & \\
\hline IRI (m/km) & 1.42 & 1.42 & 1.38 & & \\
\hline Long. cracking (m/km) & 0.00 & 0.00 & 0.02 & & \\
\hline Alligator Cracking (\%) & 0.20 & 0.20 & 0.10 & & \\
\hline Transverse Cracking (m/km) & 0.19 & 0.19 & 0.19 & & \\
\hline AC permanent deformation $(\mathrm{cm})$ & 0.23 & 0.23 & 0.25 & & \\
\hline Total permanent deformation $(\mathrm{cm})$ & 0.93 & 0.93 & 0.75 & & \\
\hline
\end{tabular}

*indicates failure.

total permanent deformation decrease with an increase

in the subgrade modulus. There is no failure at any 
subgrade modulus level.

\subsection{Effect of Reliability}

The effect of reliability has been investigated by keeping the distress target at default values and changing the reliability to $50 \%$. All projects failed in total permanent deformation and there has not been any increase in maximum service life due to the change in reliability under existing traffic condition. Higher traffic values have been used to investigate the effect of reliability and maximum service life is higher using $50 \%$ reliability than that of $90 \%$. The results have not been included since the results are the same under the existing conditions.

\subsection{Effect of Distress Target}

The effect of distress targets on the maximum service of projects in this study has been investigated using Criteria 2 in Table 2. There has not been a change in the maximum design life due to the changes in distress targets under the existing conditions.

\section{Conclusions}

Based on this study, the following conclusions have been made:

MEPDG design analysis of flexible pavements designed using 1993 AASHTO design guide does not show the default distresses currently observed in Kansas in the 10-year design period. By the end of 10 -year design period, over $50 \%$ of pavements have had some form of structural rehabilitation from KDOT's experience.

The MEPDG analysis results also show that the thinner the pavement sections, the higher the asphalt concrete layer and total permanent deformation.

The existing pavement structures can serve for more than 20 years as per the MEPDG design analysis if the nationally calibrated models and default failure criteria are used. This is contrary to the current Kansas experience that shows that by year 20 nearly all pavements have had some kind of structural rehabilitation.

Total AC thickness varies from $7.5 \mathrm{~cm}$ to $15 \mathrm{~cm}$ for a 10-year design period if the effect of AC surface down cracking (longitudinal cracking) is ignored. The lowest thickness is observed on $\mathrm{K}-7$, which has 27.5 cm of AB-3.

The minimum total AC thickness to serve for 10 -year period considering the longitudinal cracking varies from $15 \mathrm{~cm}$ to $22.5 \mathrm{~cm}$. The lowest IRI is observed on a pavement that has the highest total AC thickness and vice versa. Longitudinal cracking does not depend on the thickness of AC layers.

Back-calculated subgrade moduli obtained from various back-calculation programs result in variable predicted distresses for different projects.

Distress target and reliability have not shown significant effects on the maximum service life of the existing pavements. This needs to be verified by performance observation of in-service pavements.

\section{References}

[1] Guide for Design of Pavement Structures, AASHTO (American Association of State Highway and Transportation Officials), Washington D.C., 1986.

[2] Guide for Design of Pavement Structures, AASHTO (American Association of State Highway and Transportation Officials), Washington D.C., 1993.

[3] K.T. Hall, State of the Art and Practice in Rigid Pavement Design, Transportation in the New Millennium, Transportation Research Board, Washington, D.C., 2000.

[4] Guide for Mechanistic-Empirical Design of New and Rehabilitated Pavement Structures, Final NCHRP report for Project 1-37A, Transportation Research Board, Washington, D.C., 2004.

[5] M.W. Witczak, T.K. Pellinen, M.M. El-Basyouny, Pursuit of the simple performance test for asphalt concrete fracture/cracking, Journal of the Association of Asphalt Paving Technologists 71 (2002) 767-778.

[6] Simple Performance Test for Superpave Mix Design, NCHRP report 465, Transportation Research Board, Washington, D.C., 2002.

[7] Interim User Manual for the M-E Pavement Design Guide, NCHRP, Transportation Research Board, Washington, D.C., 2007.

[8] Y.J. Chou, R.L. Lytton, Accuracy and consistency of 
back-calculated pavement layer moduli, Transportation Research Record: Journal of the TRB 1022 (1991) 1-7.

[9] R.W. Meier, D.R. Alexander, R.B. Freeman, Using artificial neural networks as a forward approach to back-calculation, Transportation Research Record:
Journal of the TRB 1570 (1997) 126-133.

[10] T.F. Fwa, C.Y. Tan, W.T. Chan, Back-calculation analysis of pavement-layer moduli using genetic algorithms, Transportation Research Record: Journal of the TRB 1570 (1997) 134-142. 